\section{(C) OPEN ACCESS}

\title{
Epidemiology of ALS in Korea using nationwide big data
}

\author{
Kyo Yeon Jun, ${ }^{1,2}$ Jinseok Park, ${ }_{1}^{3,4}$ Ki-Wook Oh, ${ }^{3,4}$ Eun Mi Kim, ${ }^{1}$ Jong Seok Bae, ${ }^{5}$ \\ Inah Kim, ${ }^{1,6}$ Seung Hyun Kim ${ }^{3,4}$
}

- Additional material is published online only. To view please visit the journal online (http://dx.doi.org/10.1136/ innp-2018-318974)

For numbered affiliations see end of article.

\section{Correspondence to}

Inah Kim, Occupational and Environmental Medicine

College of Medicine, Hanyang University, Seoul 04763,

Republic of Korea; inahkim@ hanyang.ac.kr and Professor Seung Hyun Kim, Department of Neurology, College of Medicine, Hanyang University, Seoul 04763, Korea; kimsh1@ hanyang.ac.kr

KYJ, JP, IK and SHK contributed equally.

Received 8 June 2018 Revised 21 September 2018 Accepted 1 October 2018 Published Online First 8 November 2018

\section{ABSTRACT \\ Objective This study aimed to determine the incidence, prevalence and survival time of Korean patients with amyotrophic lateral sclerosis (ALS) using National Health Insurance Service (NHIS) data.}

Methods Using NHIS data, the Korean nationwide health dataset, we identified patients with motor neuron diseases who were first diagnosed with a KCD-6 code (G12.20-G12.28; modified from ICD-10 codes) between 2011 and 2015. ALS (G12.21 code) epidemiological characteristics, including annual incidence, prevalence, mortality rates and survival time, were analysed and compared with sociodemographic variables.

Results New patients with ALS ( $n=3049$ ) were enrolled over 5 years. The mean annual incidence was 1.20/100 000 , and the sex ratio was 1.60 (male:female). The mean age at the time of diagnosis was 61.4 years. The prevalence rate was 3.43/100 000 in 2015. In this period, riluzole was prescribed to $53.6 \%$ of patients with ALS. Furthermore, $20.3 \%$ of patients with ALS underwent tracheostomy. When analysed for age and socioeconomic status, ALS prevalence rate was 10.71 in the aged group $(\geq 60)$ in 2015 and was lowest in the middle-income group compared with that in the high-income and lowincome groups. The estimated mean survival time in this population was 50.0 months, and the 3-year and 5-year mortality rates were $52.1 \%$ and $63.7 \%$, respectively. Conclusions This study is the first nationwide survey for epidemiological characteristics of ALS in Korea using national data. The use of these data substantially advances the understanding of Korean and Asian ALS epidemiology and its relationship with socioeconomic status, age and sex.

\section{INTRODUCTION}

Amyotrophic lateral sclerosis (ALS) is a neurodegenerative disease characterised by the progressive degeneration of motor neurons, which leads to impairment of limb and bulbar function and ultimately death due to respiratory failure. ${ }^{12}$ Despite considerable recent advances in clinical and basic research on ALS, its clinical heterogeneity remains poorly understood. ${ }^{3}$ Recent studies on ethnic differences in ALS's causative genes, the role of environmental factors in its aetiology and a conceptual paradigm shift from understanding ALS as a classic motor neuron disease to a motor network syndrome may collectively provide some clues for better understanding the racial differences underlying ALS's unique epidemiology and prognosis. ${ }^{45}$
The incidence of ALS in European studies was reported as $2-3$ per $100000,{ }^{6-8} 0.3-0.6$ in Taiwan and China ${ }^{9-11}$ and 1.68 person-years of follow-up (PYFU) worldwide. ${ }^{12}$ The survival time from disease onset is also considerably variable by population ${ }^{13}$; it was reported to be 30 months in European samples, ${ }^{6} 71$ months in China ${ }^{1}$ and 48 months in Japan. ${ }^{14}$ The epidemiological characteristics of patients with ALS are variable by patient nationality, region and race. In addition, studies on the epidemiological characteristics of ALS have been conducted mostly in Europe and North America, whereas those in Asia have been limited. ${ }^{7}$ It should be noted that even within Asian countries, epidemiological data are dissimilar, ${ }^{15}$ and Korean data have been limited to one cross-sectional study. ${ }^{16} \mathrm{We}$ assumed that these differences in epidemiological data in ALS were due to ethnic or genetic differences and also to heterogeneity of the denominator databases, such as a nationwide population-based study, hospital-based study or registry-based study. In this study, we conducted an epidemiological study using a nationwide population-based database. The present study sought to investigate the incidence, prevalence and survival of ALS based on population-based Korean National Health Insurance Database (NHID) data.

\section{MATERIALS AND METHODS}

\section{National health insurance in Korea}

National Health Insurance System (NHIS) coverage in Korea is provided by a single insurer (the central government) for the entire population and as such follows a social health insurance scheme. As of $2016,97.1 \%$ of the population was covered by health insurance, and 2.9\% were covered by medical aid. ${ }^{17}$

NHIS in Korea provides data through the National Health Insurance Database (NHID) for research purposes only. These data include information on the insured population's sociodemographic characteristics, income-based insurance contributions, medical treatment records, long-term care insurance information for elderly patients, the status of medical institutions, and rates of cancer and rare incurable diseases.

In Korea, all medical institutions nationwide are contracted by the national government under a mandatory system and operate based on a regulated fee-for-service system. All prescriptions, orders and diagnostic codes are computerised and gathered in the NHID. Given this, the NHID provides data that 
more accurately represent the entire population than an individual, smaller sample could. Therefore, we used the NHID here to derive the most accurate epidemiological data for the entire Korean population.

\section{Korean Classification of Disease (KCD) code for motor neuron diseases and diagnosis rates}

Statistics Korea has developed the Korean Classification of Disease (KCD 5-7) based on International Classification of Disease and Related Health Problems 10th Revision (ICD-10). Until 2010, all patients with ALS or other types of motor neuron diseases (MNDs) were designated with a G12.2 code, which aligns with a KCD-5 code. Therefore, it was impossible to identify sporadic or familial forms of ALS from a spectrum of MNDs in the NHID until 2010. In 2011, however, more detailed codes (G12.20-G12.28 or KCD-6) were adopted to differentiate between specific types of MNDs. For example, familial and sporadic ALS were coded as G12.20 and G12.21, respectively, and G12.22 (primary lateral sclerosis), G12.23 (progressive bulbar palsy), G12.24 (progressive muscular atrophy) and G12.28 (other and unspecified motor neuron disease) were further subclassified within the broader KCD-6 category.

In the present study, novel G12.21 (KCD-6) codes identified at least once in the NHID between January 2011 and December 2015 were used to define newly registered, sporadic patients with ALS. Although these patients were not classified based on the El Escorial Criteria-Revised categories (clinically definite, clinically probable, clinically probable with laboratory supportive, or clinically possible), they were compatible with one of them. ${ }^{18}$

The total number of patients diagnosed with a G12.20G12.28 code was 7672 between 2011 and 2015, and the number of sporadic patients with ALS with a G12.21 code was 3049 in the same period. These constituted our final study subjects for survival analysis.

\section{Incidence, prevalence and survival time of Korean patients with ALS}

From 2011 to 2015, newly registered patients with ALS and the standard population (denominator) in each year were identified using a NHID subdatabase (DB) - the healthcare use DB and the eligibility DB. During the study period, the population of Korea (denominator) was ageing. In 2011, the population over the age of 60 was $15.3 \%$, which increased to $17.6 \%$ in 2015 . Compared with the WHO standard population (2000-2025), ${ }^{19}$ which is $11.95 \%$ over 60 , Korea has a large population of elderly people. The male:female ratio was almost 1.00 in all years. The crude incidence and prevalence per 100000 inhabitants were calculated using the standard population. Additionally, we calculated age-adjusted incidence and prevalence using the world standard population (WHO 2000-2025). ${ }^{19}$ Furthermore, the prevalence of each MND code (G12.20-G12.28) identified in the NHID and based on a KCD- 6 code was also analysed for the purpose of detecting sporadic ALS from the other MNDs. In cases where the MND diagnosis ascribed to a particular patient changed within a year, it was defined as the last diagnosis assigned that year.

In this study, we analysed the relationship between ALS and socioeconomic status, incidence and prevalence rate. 'Income' was categorised by income-based insurance contribution level. The 'highest income group' paid the highest insurance contributions and was consequently expected to have attained the highest socioeconomic level. 'Region' was categorised by 'Seoul city', which is the capital of South Korea, other 'metropolitan city', or those cities excluding Seoul, and 'other areas', which included small and medium cities as well as rural areas.

In addition, we analysed the percentage of patients who had taken riluzole at least once and number of patients who underwent a tracheostomy during the follow-up period. Sociodemographic variables were divided according to status at the time point of first diagnosis, and the use of riluzole and/or undergoing a tracheostomy were counted at the time of event occurred during the follow-up period. Tracheostomy operations were identified by insurance payment code O1300 (invasive tracheostomy) and/or O1301 (percutaneous dilatational tracheostomy) and appropriate subcodes.

\section{Mean survival time of Korean patients with ALS}

The survival rate and the survival time from first diagnosis of patients with ALS were analysed using Kaplan-Meier survival curves. The starting point for these analyses was defined as the date of first diagnosis. The ending point was defined as either the date of death or as 30 April 2017 for those who continued to live at study termination.

For the 3049 patients diagnosed with ALS between 2011 and 2015 , patient follow-up duration ranged from a minimum of 1.33 years to a maximum of 6.33 years after first diagnosis. Previously published survival times for patients with ALS are 3-6 years. ${ }^{1614}$ Some subjects' data were not sufficient to analyse survival time. Therefore, survival rates and survival time from first diagnosis were analysed in two different groups. That is, these analyses were independently performed on all patients $(\mathrm{N}=3049)$ and also in a subgroup that only included patients whose follow-up time was longer than 5 years after first diagnosis $(\mathrm{N}=714)$. Sociodemographic characteristics, mortality rates and mean survival time were also compared between these two groups. We analysed survival curves affected by factors including the age of diagnosis, residence and socioeconomic status using the Kaplan-Meier survival curves.

\section{Diagnostic delay}

Using the NHID offers the significant benefit that the time of first diagnosis is likely to be highly accurate. This is because ALS is classified as a rare intractable disease (RID) in Korea, meaning that patients with ALS are financially supported by the government RID registry programme and have co-payment reduction benefits.

Accurately determining the duration from the time of symptom onset to ALS diagnosis (diagnostic delay) was challenging. Diagnostic delay was the mean time duration between symptom onset to the time of first diagnosis. We estimated this mean diagnostic delay time from data provided by the ALS clinic in the department of neurology at Hanyang University Hospitals in Seoul, Korea. Diagnostic delay was estimated from 299 patients with ALS between March 2009 and June 2017. All patients fulfilled the revised El Escorial criteria. The mean diagnostic delay was 11.7 months (median, 9 months). Given this, we performed true survival time estimates by adding 11.7 months to survival time after first diagnosis.

\section{Statistical analyses}

We calculated the estimated incidence and prevalence of ALS per 100000 inhabitants using the eligibility DB's annual total population as the standard population. We also calculated $95 \%$ CIs. Variables including age at first diagnosis, sex, income level and region of residence were analysed to determine whether any affected ALS incidence or prevalence rates and/or survival time. 
Table 1 Total number of newly enrolled patients with amyotrophic lateral sclerosis (ALS) and incidence rates per 100000 inhabitants in Korea (2011-2015)

\begin{tabular}{|c|c|c|c|c|c|}
\hline Parameters at first diagnosis & $\begin{array}{l}\text { Total number (\%) of new } \\
\text { patients with ALS* }\end{array}$ & Use of riluzole \% & Tracheostomy \% & $\begin{array}{l}\text { Incidence } \\
\left(\text { per } 10^{5}\right) \dagger\end{array}$ & $95 \% \mathrm{Cl}$ \\
\hline \multicolumn{6}{|l|}{ Age } \\
\hline$<40$ & $140(4.6)$ & 35.7 & 10.7 & 0.11 & 0.07 to 0.15 \\
\hline $40-49$ & $335(11.0)$ & 60.9 & 16.4 & 0.76 & 0.58 to 0.94 \\
\hline $50-59$ & $782(25.6)$ & 58.2 & 20.6 & 2.04 & 1.72 to 2.35 \\
\hline$\geq 60$ & $1792(58.8)$ & 51.6 & 21.7 & 4.29 & 3.85 to 4.74 \\
\hline \multicolumn{6}{|l|}{ Sex } \\
\hline Male & $1878(61.6)$ & 51.8 & 21.5 & 1.47 & 1.32 to 1.62 \\
\hline Female & $1171(38.4)$ & 56.4 & 18.4 & 0.92 & 0.80 to 1.04 \\
\hline \multicolumn{6}{|l|}{ Incomeł } \\
\hline High & $1088(35.7)$ & 53.3 & 22.3 & 1.30 & 1.13 to 1.48 \\
\hline Middle & $1174(38.5)$ & 56.0 & 20.4 & 1.01 & 0.88 to 1.14 \\
\hline Low & $787(25.8)$ & 50.3 & 17.3 & 1.41 & 1.19 to 1.63 \\
\hline \multicolumn{6}{|l|}{ Region } \\
\hline Seoul city§ & $601(19.7)$ & 55.9 & 21.8 & 1.19 & 0.97 to 1.40 \\
\hline Metropolitanף & $707(23.2)$ & 54.5 & 21.8 & 1.09 & 0.91 to 1.27 \\
\hline Other areas** & 1741 (57.1) & 52.4 & 19.2 & 1.25 & 1.11 to 1.38 \\
\hline Total & $3049(100.0)$ & 53.6 & 20.3 & 1.20 & 1.10 to 1.29 \\
\hline adjusted incidencet† & & & & 0.88 & 0.81 to 0.95 \\
\hline Age at diagnosis (mean $\pm S D$ ) & $61.4 \pm 12.4$ & & & & \\
\hline Male:female ratio & 1.60 & & & & \\
\hline \multicolumn{6}{|c|}{$\begin{array}{l}\text { *5 years (2011-2015) total number of new patients. } \\
\text { †Crude incidence rate per } 100000 \text { inhabitants. } \\
\text { †Income-based insurance contributions. } \\
\S \text { Seoul metropolitan city. } \\
\text { १Other metropolitan cities. } \\
\text { ** Non-metropolitan area. }\end{array}$} \\
\hline
\end{tabular}

Mean survival time and survival rate were calculated using the Kaplan-Meier method. A log-rank test was used to analyse the difference of survival time between sociodemographic variables. In addition, 3-year and 5-year mortality rates were also analysed. All data analyses were performed using the SAS Enterprise Guide software (V.7.1; SAS Institute, Cary, North Carolina, USA).

\section{Data availability policy}

Anonymised data will be shared by request from any qualified investigator.

\section{RESULTS}

Incidence and prevalence of ALS in Korea

The total number of new patients with ALS analysed across the 5 years was 3049, with an annual crude incidence per 100 000 inhabitants of 1.20 and an age-adjusted incidence of 0.88 . The mean age at the time of diagnosis was 61.4 years, and the male:female ratio was 1.60 (table 1). The proportion of first-diagnosed patients with ALS were highest at the age of 60-69 years and started to decline at age 70 years (online supplementary figure e-1). The crude prevalence rate in 2015 was 3.43, and age-adjusted prevalence rate was somewhat lower than the crude rate (2.38) (table 2).

In 2015,1770 patients with ALS visited the hospital at least once, and of these, 973 (55\%) were 60 years or older. The demographic distribution of ALS prevalence did not significantly differ by year. However, prevalence was slightly lower in the middle-income group than in the high-income and low-income groups (table 2), similar to the incidence rate described in table 1.
Riluzole, the only medication approved by the FDA for the treatment of ALS at the time, was prescribed to $53.6 \%$ of all patients. The rate of patients undergoing a tracheostomy during the follow-up period was $20.3 \%$ and did not differ by age, sex, income level or region except for a decreased rate of riluzole prescription in individuals who experienced ALS onset at a young age $(<40$ years) (table 1$)$.

\section{Proportion of patients with ALS in MND spectrum (G12.20- G12.28) in NHID}

To compare the proportion of sporadic ALS (G12.21) with that of other MNDs (G12.20-G12.28), we analysed the number and proportion of each MND in the NHID.

After adopting the KCD-6 code system in 2011, the percentage of sporadic ALS (G12.21) diagnosed individuals across all MND cases (G12.20-G12.28) was approximately 50\%. Of those with MND, familial ALS (G12.20, KCD-6) represented about 2.0\% of the full MND spectrum, findings which mirror assumed rates based on previous genetic data. ${ }^{20}$ Across the MND spectrum, the combined proportion of G12.22 (primary lateral sclerosis), G12.23 (progressive bulbar palsy) and G12.24 (progressive muscular atrophy) was less than $10 \%$ (table 3 ).

\section{Mortality}

To validate and compare mortality across differing follow-up periods, which could have varying degrees of error, we analysed mortality by follow-up duration. By April 2017, 1635 (53.6\%) of the total patients $(n=3049)$ and $470(65.8 \%)$ of subgroup patients $(n=714)$ had died. 
Table 2 Epidemiological and socioeconomic characteristics of patients with amyotrophic lateral sclerosis and annual incidence and prevalence per 100000 in Korea

\begin{tabular}{|c|c|c|c|c|c|c|c|c|c|c|c|c|c|c|}
\hline \multirow{3}{*}{$\begin{array}{l}\text { Year } \\
\text { Characteristics at first } \\
\text { diagnosis }\end{array}$} & \multicolumn{10}{|c|}{ Incidence } & \multicolumn{4}{|c|}{ Prevalence } \\
\hline & \multicolumn{2}{|c|}{2011} & \multicolumn{2}{|c|}{2012} & \multicolumn{2}{|c|}{2013} & \multicolumn{2}{|c|}{2014} & \multicolumn{2}{|l|}{2015} & \multicolumn{2}{|l|}{2011} & \multicolumn{2}{|l|}{2015} \\
\hline & $N$ & Inc* & $\mathrm{N}$ & Inc* & $\mathrm{N}$ & Inc* & $\mathrm{N}$ & Inc* & $\mathrm{N}$ & Inc* & $\mathrm{N}$ & Pret & $\mathrm{N}$ & Pret \\
\hline \multicolumn{15}{|l|}{ Age } \\
\hline$<40$ & 38 & 0.14 & 27 & 0.10 & 23 & 0.09 & 22 & 0.09 & 30 & 0.12 & 75 & 0.28 & 63 & 0.25 \\
\hline $40-49$ & 64 & 0.73 & 73 & 0.83 & 62 & 0.70 & 73 & 0.82 & 63 & 0.71 & 195 & 2.22 & 225 & 2.52 \\
\hline $50-59$ & 139 & 1.99 & 157 & 2.10 & 147 & 1.90 & 162 & 2.03 & 177 & 2.16 & 382 & 5.46 & 509 & 6.20 \\
\hline$\geq 60$ & 264 & 3.43 & 392 & 4.93 & 342 & 4.10 & 385 & 4.44 & 409 & 4.50 & 685 & 8.89 & 973 & 10.71 \\
\hline \multicolumn{15}{|l|}{ Sex } \\
\hline Male & 315 & 1.25 & 383 & 1.51 & 336 & 1.32 & 411 & 1.60 & 433 & 1.68 & 807 & 3.19 & 1072 & 4.15 \\
\hline Female & 190 & 0.75 & 266 & 1.05 & 238 & 0.93 & 231 & 0.90 & 246 & 0.95 & 530 & 2.11 & 698 & 2.71 \\
\hline \multicolumn{15}{|l|}{ Incomeł } \\
\hline High & 178 & 1.09 & 235 & 1.42 & 184 & 1.10 & 247 & 1.47 & 244 & 1.44 & 468 & 2.85 & 611 & 3.61 \\
\hline Middle & 195 & 0.85 & 246 & 1.07 & 221 & 0.95 & 247 & 1.06 & 265 & 1.14 & 494 & 2.15 & 624 & 2.68 \\
\hline Low & 132 & 1.19 & 168 & 1.51 & 169 & 1.53 & 148 & 1.33 & 170 & 1.50 & 375 & 3.38 & 535 & 4.72 \\
\hline \multicolumn{15}{|l|}{ Region } \\
\hline Seoul city§ & 95 & 0.93 & 130 & 1.29 & 108 & 1.06 & 127 & 1.25 & 141 & 1.39 & 301 & 2.94 & 408 & 4.03 \\
\hline Metropolitanף & 124 & 0.96 & 130 & 1.03 & 144 & 1.11 & 153 & 1.17 & 156 & 1.19 & 331 & 2.57 & 402 & 3.07 \\
\hline Other areas** & 286 & 1.05 & 389 & 1.38 & 322 & 1.16 & 362 & 1.29 & 382 & 1.35 & 705 & 2.58 & 960 & 3.38 \\
\hline Total & 505 & $1.00+\dagger$ & 649 & $1.28+\dagger$ & 574 & $1.13+t$ & 642 & $1.25 t \dagger$ & 679 & $1.32+\dagger$ & 1337 & $2.65+\dagger$ & 1770 & $3.43+\dagger$ \\
\hline Adjusted incidence/prevalence & & $0.79 \ddagger \ddagger$ & & $0.97 \ddagger \ddagger$ & & $0.83 \ddagger \ddagger$ & & $0.89 \ddagger \ddagger$ & & $0.92 \ddagger \ddagger$ & & $2.07 \ddagger \ddagger$ & & $2.38 \neq \ddagger$ \\
\hline
\end{tabular}

*Incidence rate per 100000 inhabitants in Korea.

†Prevalence rate per 100000 inhabitants in Korea.

‡Income-based insurance contributions.

$\S$ Seoul metropolitan city.

ๆ0ther metropolitan cities.

${ }^{* *}$ Non-metropolitan area.

t+Crude rate.

¥¥Age-adjusted incidence/prevalence (per 100000 inhabitants) using WHO (2000-2025) world standard population.

The mortality was higher among the older age of onset group compared with the younger age of onset group. In the subgroup (the long-term follow-up group), the mortality of female patients was higher than that of male patients, and the middle-income group had the highest mortality. Analysis by region revealed a lower mortality among Seoul city residents than that of metropolitan cities or other areas, regardless of sampling method. Finally, the 3-year ALS mortality in this sample was $52.1 \%$, and the 5-year mortality was 63.7 (table 4).

In many epidemiological studies of ALS, tracheostomy has been considered as death. Therefore, we performed an additional analysis with a new end-point treating tracheostomy as death; we called this the functional end-point. The functional end-point rate was $60.5 \%$ of the total patients $(n=3049)$ and
$72.8 \%$ of the subgroup patients $(\mathrm{n}=714)$. These results were $6.9 \%$ and $7.0 \%$ higher, respectively, than when tracheostomy is not considered as death (table 4).

\section{Survival time from first diagnosis and symptom onset}

As with mortality, survival time was also analysed among total subjects and in the subgroup. Corrected survival time was calculated by adding the mean diagnostic delay (11.7 months) to the survival time after the first diagnosis, as explained in the Materials and methods section.

The mean survival time from first diagnosis was not significantly different between the two groups (38.3 months in the

Table 3 Proportion of amyotrophic lateral sclerosis in the motor neuron disease spectrum (G12.20-G12.28) from 2011 to 2015

\begin{tabular}{|c|c|c|c|c|c|c|}
\hline KCD-6 code* & Classification of motor neuron diseases & $\begin{array}{l}2011 \\
\text { N (\%) }\end{array}$ & $\begin{array}{l}2012 \\
\text { N (\%) }\end{array}$ & $\begin{array}{l}2013 \\
\mathrm{~N}(\%)\end{array}$ & $\begin{array}{l}2014 \\
\text { N (\%) }\end{array}$ & $\begin{array}{l}2015 \\
\text { N (\%) }\end{array}$ \\
\hline G12.20 & Familial motor neuron disease & $67(2.4)$ & $61(2.2)$ & $72(2.4)$ & $67(2.0)$ & $66(1.9)$ \\
\hline G12.21 & Amyotrophic lateral sclerosis & $1337(48.2)$ & $1462(52.6)$ & $1521(50.4)$ & $1676(50.1)$ & $1770(50.0)$ \\
\hline G12.22 & Primary lateral sclerosis & $46(1.7)$ & $67(2.4)$ & $68(2.3)$ & $69(2.1)$ & $92(2.6)$ \\
\hline G12.23 & Progressive bulbar palsy & $112(4.0)$ & $122(4.4)$ & $136(4.5)$ & $186(5.6)$ & $185(5.2)$ \\
\hline G12.24 & Progressive spinal muscular atrophy & $68(2.5)$ & $59(2.1)$ & $47(1.6)$ & $55(1.6)$ & $57(1.6)$ \\
\hline \multirow[t]{2}{*}{ G12.28 } & Other and unspecified motor neuron disease & $1145(41.3)$ & $1011(36.3)$ & $1173(38.9)$ & $1293(38.6)$ & $1373(38.8)$ \\
\hline & Total & $2775(100.0)$ & $2782(100.0)$ & $3017(100.0)$ & $3346(100.0)$ & $3543(100.0)$ \\
\hline
\end{tabular}

*The KCD-6 is modified from the ICD-10.

$K C D$, Korean Classification of Disease. 
Table 4 Mortality (only death) and functional end-point (tracheostomy or death) of patients with amyotrophic lateral sclerosis

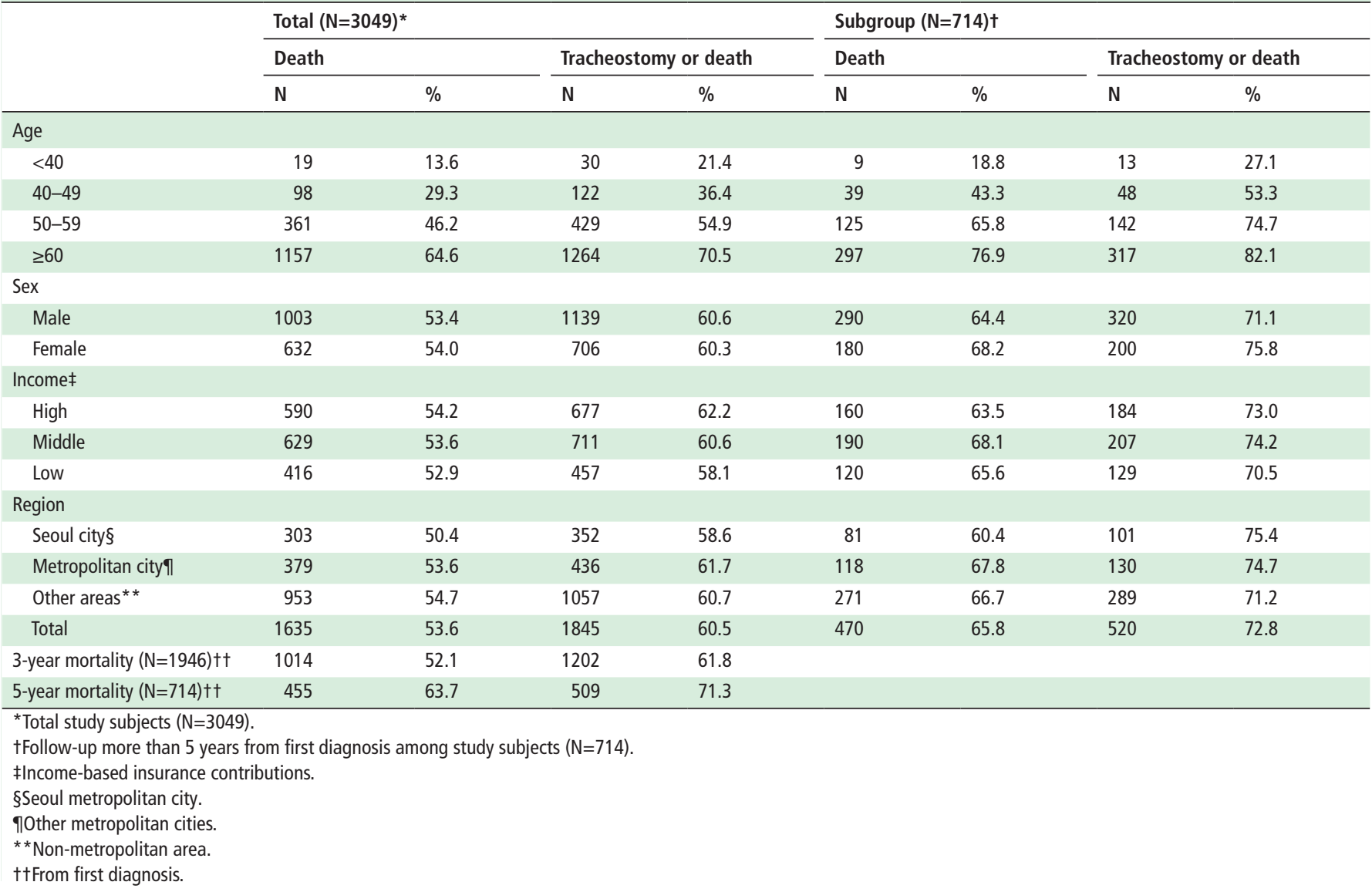

total subject population $(\mathrm{n}=3049)$ and 38.0 months in the subgroup (long-term follow-up group)).

When comparing the survival time between groups according to demographic and socioeconomic status factors, we detected only a significant difference in the mean survival time by age of onset (figure 1). Among all subjects, the survival time in the young age onset group ( $<40$ years) was 57.7 months, while that among the old age onset group ( $\geq 60$ years) was 31.4 months (table 5).

When comparing actual death and the functional end-point (tracheostomy or death), functional end-point has a shorter survival time than actual death in the total subjects $(n=3049)$. The survival time of functional end-point was 33.5 months from first diagnosis, which is 4.8 months shorter than that of actual

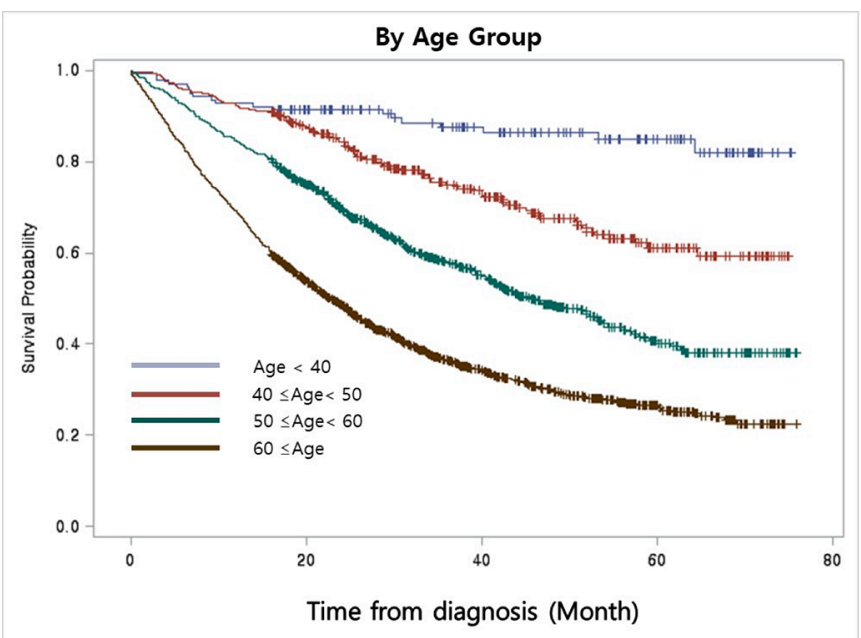

A From diagnosis to real death $(\mathrm{N}=3,049)$

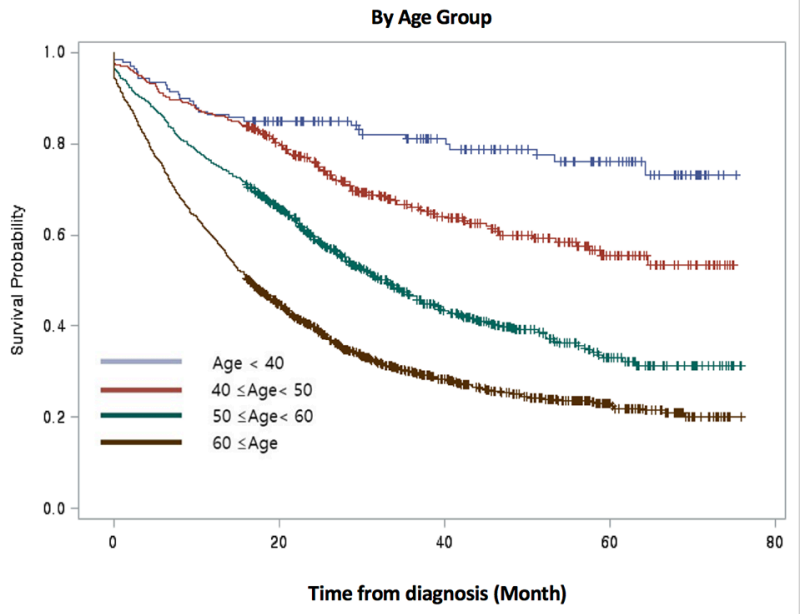

B From diagnosis to real death or tracheostomy $(\mathrm{N}=3,024)$

Figure 1 Comparison of the survival curves from the time of diagnosis to the time of death in patients with amyotrophic lateral sclerosis shows significant differences in symptom onset age (2011-2015). This shows that the younger symptom onset age group had relatively longer survival time compared with that of the older group (log-rank test, $p<0.0001$, both). 
Table 5 Mean survival time from first diagnosis to death (or to the end of follow-up time) or to tracheostomy or death (or to the end of follow-up time)

\begin{tabular}{|c|c|c|c|c|c|c|c|c|c|c|c|c|}
\hline & \multicolumn{6}{|c|}{ Total $(\mathrm{N}=3049)^{*}$} & \multicolumn{6}{|c|}{ Subgroup $(N=714) \dagger$} \\
\hline & \multicolumn{3}{|l|}{ Death } & \multicolumn{3}{|c|}{ Tracheostomy or death } & \multicolumn{3}{|l|}{ Death } & \multicolumn{3}{|c|}{ Tracheostomy or death } \\
\hline & Mean§ & SE & P valuesף & Mean§ & SE & P valuesף & Mean§ & SE & P valuesף & Mean§ & SE & $P$ valuesף \\
\hline \multicolumn{13}{|l|}{ Age } \\
\hline$<40$ & 57.7 & 1.52 & $<0.0001$ & 53.4 & 1.87 & $<0.0001$ & 57.4 & 2.57 & $<0.0001$ & 65.4 & 3.06 & $<0.0001$ \\
\hline $40-49$ & 50.8 & 1.19 & & 46.4 & 1.36 & & 50.0 & 2.14 & & 54.5 & 2.52 & \\
\hline $50-59$ & 40.9 & 0.86 & & 35.3 & 0.91 & & 37.9 & 1.69 & & 40.9 & 1.95 & \\
\hline$\geq 60$ & 31.4 & 0.64 & & 27.0 & 0.64 & & 30.8 & 1.29 & & 31.5 & 1.35 & \\
\hline \multicolumn{13}{|l|}{ Sex } \\
\hline Male & 36.9 & 0.60 & 0.9446 & 31.9 & 0.62 & 0.6788 & 37.0 & 1.17 & 0.4278 & 39.7 & 1.33 & 0.4384 \\
\hline Female & 38.3 & 0.82 & & 33.7 & 0.84 & & 37.4 & 1.62 & & 38.5 & 1.72 & \\
\hline \multicolumn{13}{|l|}{ Income** } \\
\hline High & 36.1 & 0.79 & 0.6515 & 31.0 & 0.81 & 0.1211 & 37.4 & 1.55 & 0.4472 & 40.4 & 1.77 & 0.5236 \\
\hline Middle & 37.5 & 0.77 & & 32.6 & 0.80 & & 35.6 & 1.52 & & 37.6 & 1.68 & \\
\hline Low & 39.0 & 1.00 & & 35.2 & 1.04 & & 38.8 & 1.94 & & 40.0 & 2.06 & \\
\hline \multicolumn{13}{|l|}{ Region } \\
\hline Seoul city†† & 38.8 & 1.05 & 0.0915 & 32.9 & 1.09 & 0.6661 & 41.7 & 1.99 & 0.0887 & 44.2 & 2.23 & 0.5823 \\
\hline Metropolitan citył‡ & 37.8 & 1.03 & & 30.1 & 0.92 & & 34.8 & 2.01 & & 36.4 & 2.17 & \\
\hline Other areas§§ & 37.6 & 0.67 & & 33.5 & 0.69 & & 37.4 & 1.31 & & 38.6 & 1.39 & \\
\hline Total & 38.3 & 0.51 & & 33.5 & 0.52 & & 38.0 & 0.99 & & 39.2 & 1.05 & \\
\hline
\end{tabular}

All lengths of time are in months.

${ }^{*}$ Total study subjects $(\mathrm{N}=3049)$.

tFollow-up more than 5 years from first diagnosis among study subjects $(\mathrm{N}=714)$.

¥In total study subjects, there were 25 patients who had an invalid tracheostomy date (underwent tracheostomy before amyotrophic lateral sclerosis diagnosis). When

calculating functional end-point survival time in total patients group, we excluded those 25 patients ( $N=3024)$.

$\S$ Mean survival time from first diagnosis to death or to functional end-point (or to the end of follow-up time).

IP value by log-rank test.

** Income-based insurance contributions.

††Seoul metropolitan city.

$\ddagger \ddagger$ Other metropolitan cities.

$\S \S$ Non-metropolitan area.

death. However, in the subgroup (long-term follow-up group) analysis, survival time of functional end-point was somewhat longer (39.2 months) than that of real death (38.0 months) (table 5).

The mean diagnostic delay was analysed for all 299 patients with ALS treated at Hanyang University Hospital and was found to be $11.66 \pm 8.91$ months. This diagnostic delay was adopted to calculate corrected survival time, which was 50 months among the total subjects and 49.7 months in the subgroup from initial symptom onset. The mean duration from time of first diagnosis to tracheostomy was 9.5 months.

\section{DISCUSSION}

This study is the first to report the incidence, prevalence, survival rate and survival time of Korean patients with ALS using a nationwide population-based database, the NHID, which includes the entire Korean population. The subject of this study reflects the characteristics and latest trends in almost all occurrences of ALS in Korea as we analysed sociodemographic data only according to the specific G12.21 KCD-6 code (sporadic ALS).

The ALS incidence of 1.20 per 100000 estimated in the present study was lower than those reported in Europe (2.08), North America (1.80), ${ }^{8}$ Japan (2.2), ${ }^{21}$ Italy $(3.03)^{22}$ and South Germany $(2.5)^{23}$ and higher than those reported in Taiwan (0.51), China $(0.3-0.6)$ and Iran (0.73 PYFU) ${ }^{9-12}$ When comparing European data, the incidence of Korean sporadic ALS was somewhat lower. However, when other MNDs were considered (table 3), the incidence of Korean MND was similar to that previously reported in Ireland (1.89 per 100000$),{ }^{24}$ England (1.97, 1.35 per 100000$),{ }^{25}$ the Netherlands $(2.77 \text { per } 100000)^{26}$ and France $(3.32,2.72 \text { per } 100000)^{27}$ (table 6). Because the subject criteria used for incidence calculations differ across these studies, we compared the results from several national studies and further explored the diagnostic criteria used for each (table 6).

Variations in ALS and MND incidence across populations are thought to be due to differences such as population age, economic development status, healthcare system access and genetics, such as an absence of the C9orf 72 mutation. ${ }^{28}$ The incidence reported in Asian cohort studies was relatively low compared with those reported in Western-based cohort studies. The reasons why remain unclear. However, genetic differences represented by the C9orf 72 mutation have emerged as one possible cause for population diagnosis rate disparities. In a previous genetic study conducted by our group, the most common mutation in the European ALS population, the C9orf72 mutation, was absent in the Korean population. Moreover, known ALS genes, an aspect of genetic heterogeneity, have been detected at a relatively low rate in the Korean ALS population compared with that in the European population. ${ }^{29}$ Furthermore, Korean patients with ALS may have a different genetic background from other ethnicities with a low rate of familial ALS and exhibit a distinct distribution of genetic variants. Common genes including C9orf72, TARDBP and OPTN have not been found in familial and sporadic Korean patients with ALS. ${ }^{203031}$

Furthermore, these differences may arise owing to methodological heterogeneity. As shown in table 6, studies showing a 
Table 6 Comparison of incidence and prevalence rate of patients with amyotrophic lateral sclerosis (ALS) between various countries

\begin{tabular}{|c|c|c|c|c|c|c|c|c|}
\hline Study location & Race & Data source & Study design & $\begin{array}{l}\text { Diagnostic criteria } \\
\text { (for incidence) }\end{array}$ & Year & $\begin{array}{l}\text { Number of } \\
\text { new patients } \\
\text { with ALS }\end{array}$ & $\begin{array}{l}\text { Incidence* } \\
\left(\text { per } 10^{5}\right)\end{array}$ & $\begin{array}{l}\text { Prevalence* } \\
\left(\text { per } 10^{5}\right)\end{array}$ \\
\hline $\operatorname{HKSAR}^{10}$ & Chinese & $\begin{array}{l}\text { CMS (clinical } \\
\text { management } \\
\text { system) }\end{array}$ & $\begin{array}{l}\text { Hospital-based } \\
\text { (multicentre) }\end{array}$ & MND on the revised EEC+ICD-9 code $335.2,335.20-335.24$ & 1997-2002 & 98 & $0.60 \dagger$ & $3.04 \dagger$ \\
\hline $\operatorname{Japan}^{21}$ & Japanese & $\begin{array}{l}\text { Nationwide mail } \\
\text { survey }\end{array}$ & Population-based & Definite, probable or possible ALS based on the revised EEC & 2009 & 2264 & 2.2 & 9.9 \\
\hline Taiwan $^{9}$ & Chinese & Health insurance & Population-based & $\begin{array}{l}\text { Repeated claim with ICD-9 code } 335.20 \text { (amyotrophic lateral } \\
\text { sclerosis) either outpatient or inpatient }\end{array}$ & 2007 & 338 & 0.51 & 1.97 \\
\hline Ireland ${ }^{24} \ddagger$ & Caucasian & $\begin{array}{l}\text { Ireland } \neq \\
\text { MND registers }\end{array}$ & Population-based & $\begin{array}{l}\text { Definite, probable, possible and suspected MND/ALS using the } \\
\text { original EEC }\end{array}$ & $2004-2005$ & 109 & $1.89 \S$ & 4.99 \\
\hline England $^{25}$ & $\begin{array}{l}\text { European } \\
\text { origin/African } \\
\text { origin }\end{array}$ & $\begin{array}{l}\text { The South East } \\
\text { England ALS (SEALS) }\end{array}$ & Population-based & Data derived from SEALS register & $2002-2008$ & 88 & $\begin{array}{l}1.97 \S \text { ף ** } \\
1.35 \S * * \dagger \dagger\end{array}$ & $\begin{array}{l}5.7991 \\
4.94+\dagger\end{array}$ \\
\hline Netherlands ${ }^{26}$ & Caucasian & $\begin{array}{l}\text { Population-based } \\
\text { registry }\end{array}$ & Population-based & 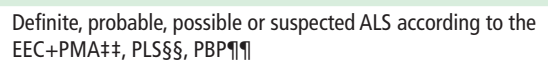 & $2006-2009$ & 1217 & $2.77 \S$ & 10.32 \\
\hline France $e^{27}$ & Caucasian & Health insurance & Population-based & $\begin{array}{l}\text { At least one delivery of riluzole or hospitalisation for MND } \\
\text { (claim with ICD-10 code G122) }\end{array}$ & 2012-2014 & 6553 & $\begin{array}{l}3.32 \S \\
2.72 \S * *\end{array}$ & NA \\
\hline Italy ${ }^{22}$ & Caucasian & PARALS*** & $\begin{array}{l}\text { Community-based } \\
\text { Cohort study }\end{array}$ & $\begin{array}{l}\text { Definite, probable or possible laboratory-supported ALS based } \\
\text { on the revised EEC (EEC before 2000) }\end{array}$ & 1995-2014 & 2702 & $\begin{array}{l}3.03 \\
2.78^{* *}\end{array}$ & 10.54 \\
\hline $\begin{array}{l}\text { Southern } \\
\text { Germany }{ }^{23}\end{array}$ & Caucasian & $\begin{array}{l}\text { The ALS registry } \\
\text { Swabia }\end{array}$ & $\begin{array}{l}\text { Community-based } \\
\text { cohort study }\end{array}$ & $\begin{array}{l}\text { Definite, probable or possible ALS based on the revised EEC } \\
\text { (cases comprise the ICD-10 code G12.2) }\end{array}$ & $2008-2010$ & 438 & $2.5+\S$ & NA \\
\hline Worldwide $^{12}$ & All races & From 44 studies & Meta-analysis & & & 13146 & $\begin{array}{l}1.75 \S \\
1.68+\S\end{array}$ & NA \\
\hline $\begin{array}{l}\text { South Korea } \\
\text { (current study) }\end{array}$ & Korean & Health insurance & Population-based & $\begin{array}{l}\text { First service claim with KCD-6 code G12.21 (amyotrophic } \\
\text { lateral sclerosis) }\end{array}$ & $2011-2015$ & 3049 & 1.20 & 3.43 \\
\hline 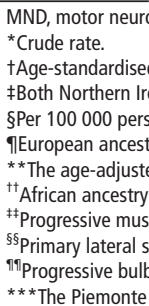 & $\begin{array}{l}\text { on disease; EEC, } \\
\text { d incidence rates. } \\
\text { eland and the Re } \\
\text { on-years. } \\
\text { ry group live in in } \\
\text { ed and sex-adjust } \\
\text { group live in inn } \\
\text { cular atrophy. } \\
\text { clerosis. } \\
\text { par palsy. } \\
\text { and Valle d'Aost }\end{array}$ & $\begin{array}{l}\text { Escorial criteria; NA, no } \\
\text { public of Ireland. } \\
\text { nner city London. } \\
\text { ted incidence rate. } \\
\text { er city London. } \\
\text { a Register for ALS. }\end{array}$ & t applicable. & & & & & \\
\hline
\end{tabular}

relatively high incidence targeted a wider range of the disease spectrum, including MND, and used hospital-based or registry-based databases. In this study, only patients with ALS (G12.21) were recruited through a nationwide population-based database, NHID. Other spectra of MND (G12.20, G12.22G12.28) were excluded to apply strictly the KCD-6 diagnostic code system, which was based on the updated ICD-10 classification system. This may explain the low incidence of ALS found in the Korean sample studied here.

We reveal here that the Korean prevalence of ALS per 100000 was 3.43 in 2015. These figures are lower than those reported by studies performed in Europe-which report 7.0-9.0 per 100 $000^{6-8}{ }^{32}$-as well as in India $(4.0)^{15}$ and Japan $(11.3),{ }^{8}$ but are similar to American estimates (3.40). ${ }^{8}$ The prevalence of ALS in China and Taiwan have been reported to be lower than what we report here in Korea. ${ }^{9-11}$ An increased prevalence in some populations may be influenced by an improved detection capability via a nationalised health registration system, especially when this system tracks patients over time rather than only on their initial registration, for the KCD-6 code G12.21 or comparable codes. ${ }^{6}$ A further factor that influences these estimates may be the accumulation of patients over time, as populations vary in terms of size and growth rates. ${ }^{9}$ Additionally, due to an increase in the use and government support of portable, at-home ventilators and the advent of clinics that use a multidisciplinary approach, the prevalence of ALS in Korea is also expected to increase gradually. ${ }^{33-35}$ Considering that the age-adjusted prevalence was lower than the crude rate and rose more slowly, the ageing population of Korea over the 5 -year study period would also have affected the prevalence (table 2).
The estimated survival time for individuals with ALS in the present study was 50 months, similar to that reported in a Japanese study (48 months) ${ }^{14}$ and in European studies (3-5 years). ${ }^{3}$ However, this Korean survival time was notably shorter than that reported in a Chinese study (median of 71 months). ${ }^{1}$ While this differed from our findings by including more severe clinical cases, the survival time of individual patients ranged from several months to over 10 years. ${ }^{113} 32$ In addition, some proportion of patients die without ever receiving a diagnosis and many regional, socioeconomic, disease awareness, accessibility of medical institutions and cultural differences exist between national populations, further increasing variability. Therefore, it is difficult to compare the survival time simply by mean or median. An additional factor that may have contributed to the increase in survival time in the Korean population reported here include the fact that ALS is part of a RID registry programme in NHIS. This programme allocates patients with RID benefits including reduced co-payments and a government-sponsored ventilator, which may provide some with a financial incentive for seeking this diagnosis. ${ }^{36-38}$

There are many reports that the use of riluzole may increase survival time in individuals with ALS. ${ }^{39-41}$ Among those with a KCD-6 code G12.21 diagnosis, the use of riluzole was $53.6 \%$ here, which is lower than the $65.3 \%$ derived from the PRO-ACT database $^{13}$ and higher than the $32.3 \%$ reported in a Chinese study. ${ }^{1}$ In Korea, it is possible to obtain riluzole with insurance benefits if an individual's ALS diagnosis meets the El Escorial revised criteria for patients with ALS diagnosed as clinically probable or clinically definite. 
A limitation of this study is that NHID is not intended or designed for research purposes, but rather for processing insurance claims, and it is thus difficult to extract completely accurate clinical progress or clinical findings data for all subjects. Furthermore, unlike hospital-based databases, individual clinical information was not included in the NHID; such information included symptom onset, onset type, progression rate, family history, result of neurological examination or laboratory tests, and history of alcohol or smoking. These data would be helpful to validate the currently available survival prediction tools such as presented by Knibb et al. ${ }^{42}$ There is also the possibility that patients who presented with atypical phenotypes were provided a non-specific code diagnosis, such as G12.28. As demonstrated in table 3, patients with a G12.28 code diagnosis (other and unspecified MND) were included more in the present cohort than was expected based on clinical experience. Additionally, we speculate that some patients with ALS do not present with clinical characteristics which fulfil the El Escorial Criteria and could have instead have been initially registered with another code, such as G12.28. Patients with other types of MNDs, such as primary lateral sclerosis or progressive bulbar palsy, which are difficult to diagnose early, may also have been assigned the G12.28 code initially. Additionally, because of the unique medical health insurance system in Korea, patients can be managed at an oriental herbal medicine hospital or nursing hospital prior to being directed to a general hospital. These patients were excluded from the present study because the accuracy of their diagnosis, even if they were assigned a G12.21 code, could not be trusted. As a result, the incidence and prevalence of this study may be somewhat underestimated. However, this also caused our research subjects to be selected by relatively strict criteria.

Despite these limitations, however, the data reported here greatly advance current understanding of the epidemiological characteristics of ALS in Korea. As with other rare diseases, it is difficult to investigate associated epidemiological data. Bae et al reported on the difficulty of collecting accurate epidemiological data on degenerative neurological disease other than ALS. ${ }^{16}$ Hardiman et al (2017) also pointed out that prospective population-based registration is a very valuable resource in assessing trends in rare diseases. ${ }^{6}$ Because NHIS is mandatory for all medical service providers and patients in Korea, we were able to collect and investigate a large quantity of epidemiological information on Korean patients with ALS. NHIS covers almost the entire Korean population (97.1\%), so the NHID represents real-world data, ${ }^{43}$ based on actual patient claims and provider billing activities.

This study is the first to report the incidence and prevalence of ALS, as well as the survival rate and time of patients with ALS, in Korea using a population-based database including almost the entire population. Through the present study, we were able to examine the scope and sociodemographic characteristics of ALS in Korea. The incidence and prevalence of ALS categories defined by income-based insurance data revealed a bimodal distribution. Furthermore, patients living outside of the city of Seoul had a shorter survival time than those living in Seoul. Based on this, we hypothesise that urban-dwelling patients access multidisciplinary medical services more easily. Between 2011 and 2015, Korean patients with ALS were classified with a KCD-6 code, as per the ICD-10. This period was selected because the disease classification was made clearer in 2011, and its duration allowed for sufficient assessment of mortality rates. Further research is needed to analyse data collected from the 5 years subsequent to 2016, when the KCD-7 was applied. Further details, including natural historical data, are also needed for a more comprehensive understanding of the characteristics of ALS and MNDs more broadly in Korea.

\section{Author affiliations}

${ }^{1}$ Department of Health Sciences, Hanyang University Graduate School, Seoul, Republic of Korea

${ }^{2}$ Occupational Safety and Health Research Institute, Korea Occupational Safety and Health Agency, Incheon, Republic of Korea

${ }^{3}$ Department of Neurology, College of Medicine, Hanyang University, Seoul, Republic of Korea

${ }^{4}$ Cell Therapy Center, Hanyang University, Seoul, Republic of Korea

${ }^{5}$ Department of Neurology, Kangdong Sacred Heart Hospital, Hallym University College of Medicine, Seoul, Republic of Korea

${ }^{6}$ Department of Occupational and Environmental Medicine, College of Medicine, Hanyang University, Seoul, Republic of Korea

Acknowledgements The authors appreciate the assistance of KOSHA (Korea Occupational Safety and Health Agency) for discussions related to the conceptualisation of this project (2015-OSHRI-1082, 2016-OSHRI-896, 2017-OSHRI-912). The National Health Information Database was provided by the National Health Insurance Service (NHIS) of Korea. The authors would like to thank the National Health Insurance Service for its cooperation. This study used NHIS-NHID data (NHIS-2016-1-111), generated by the National Health Insurance Service (NHIS) This study was supported by grants from the Korean Health Technology R\&D Project, Ministry of Health, Welfare and Family Affairs, Republic of Korea (HI16C2131) and the Brain Research Program through the National Research Foundation of Korea (NRF) funded by the Ministry of Science, ICT (NRF-2017M3C7A1025364).

Contributors IK and SHK conceived of and designed the research; KYJ and EMK collected data from the NHID; KYJ, JP, K-WO, EMK, JSB, IK and SHK analysed the data; and KYJ, JP, IK and SHK drafted the manuscript.

Funding Brain Research Program through the National Research Foundation of Korea (NRF), Korean Health Technology R\&D Project, Ministry of Health, Welfare and Family Affairs, Republic of Korea.

Disclaimer The authors alone are responsible for the content and writing of the paper.

Competing interests None declared.

Patient consent Not required.

Ethics approval The Institutional Review Board of Hanyang University approved this study (IRB: HYI-16-123-1).

Provenance and peer review Not commissioned; externally peer reviewed.

Open access This is an open access article distributed in accordance with the Creative Commons Attribution Non Commercial (CC BY-NC 4.0) license, which permits others to distribute, remix, adapt, build upon this work non-commercially, and license their derivative works on different terms, provided the original work is properly cited, appropriate credit is given, any changes made indicated, and the use is non-commercial. See: http://creativecommons.org/licenses/by-nc/4.0/.

\section{REFERENCES}

1 Chen L, Zhang B, Chen R, et al. Natural history and clinical features of sporadic amyotrophic lateral sclerosis in China. J Neurol Neurosurg Psychiatry 2015;86:1075-81.

2 Hogden A, Greenfield D, Caga J, et al. Development of patient decision support tools for motor neuron disease using stakeholder consultation: a study protocol. BMJ Open 2016;6:e010532

3 Zach N, Ennist DL, Taylor AA, et al. Being PRO-ACTive: what can a clinical trial database reveal about ALS? Neurotherapeutics 2015;12:417-23.

4 Rechtman L, Jordan $\mathrm{H}$, Wagner $\mathrm{L}$, et al. Racial and ethnic differences among amyotrophic lateral sclerosis cases in the United States. Amyotroph Lateral Scler Frontotemporal Degener 2015;16:65-71.

5 Cronin S, Hardiman O, Traynor BJ. Ethnic variation in the incidence of ALS: a systematic review. Neurology 2007;68:1002-7.

6 Hardiman O, Al-Chalabi A, Brayne C, et al. The changing picture of amyotrophic lateral sclerosis: lessons from European registers. J Neurol Neurosurg Psychiatry 2017:88:557-63.

7 Couratier P, Corcia P, Lautrette G, et al. Epidemiology of amyotrophic lateral sclerosis: a review of literature. Rev Neuro/ 2016:172:37-45.

8 Chiò A, Logroscino G, Traynor BJ, et al. Global epidemiology of amyotrophic lateral sclerosis: a systematic review of the published literature. Neuroepidemiology 2013;41:118-30.

9 Tsai CP, Wang KC, Hwang CS, et al. Incidence, prevalence, and medical expenditures of classical amyotrophic lateral sclerosis in Taiwan, 1999-2008. J Formos Med Assoc 2015;114:612-9. 
10 Fong GC, Cheng TS, Lam K, et al. An epidemiological study of motor neuron disease in Hong Kong. Amyotroph Lateral Scler Other Motor Neuron Disord 2005;6:164-8.

11 Fong KY, Yu YL, Chan YW, et al. Motor neuron disease in Hong Kong Chinese: epidemiology and clinical picture. Neuroepidemiology 1996;15:239-45.

12 Marin B, Boumediene F, Logroscino G. Variation in worldwide incidence of amyotrophic lateral sclerosis: a meta-analysis. Int J Epidemiol 2016;46:57-74.

13 Ong ML, Tan PF, Holbrook JD. Predicting functional decline and survival in amyotrophic lateral sclerosis. PLoS One 2017:12:e0174925.

14 Watanabe H, Atsuta N, Nakamura R, et al. Factors affecting longitudinal functional decline and survival in amyotrophic lateral sclerosis patients. Amyotroph Lateral Scler Frontotemporal Degener 2015;16:230-6.

15 Shahrizaila N, Sobue G, Kuwabara S, et al. Amyotrophic lateral sclerosis and motor neuron syndromes in Asia. J Neurol Neurosurg Psychiatry 2016;87:821-30.

16 Bae JS, Hong YH, Baek W, et al. Current status of the diagnosis and management of amyotrophic lateral sclerosis in Korea: a multi-center cross-sectional study. J Clin Neurol 2012;8:293-300.

17 Kim ST, Seong SC. 2016 National Health Insurance Statistical Yearbook. National Health Insurance service, 2017.

18 Brooks BR, Miller RG, Swash M, et al. El Escorial revisited: revised criteria for the diagnosis of amyotrophic lateral sclerosis. Amyotroph Lateral Scler Other Motor Neuron Disord 2000;1:293-9.

19 SEER, 2018. World (WHO 2000-2025) standard population. https://seer.cancer.gov/ stdpopulations/world.who.html (accessed 11 Aug 2018).

20 Jang JH, Kwon MJ, Choi WJ, et al. Analysis of the C9orf72 hexanucleotide repeat expansion in Korean patients with familial and sporadic amyotrophic lateral sclerosis. Neurobiol Aging 2013:34:1311.e7-1311.e9.

21 Doi Y, Atsuta N, Sobue G, et al. Prevalence and incidence of amyotrophic lateral sclerosis in Japan. J Epidemiol 2014;24:494-9.

22 Chiò A, Mora G, Moglia C, et al. Secular trends of amyotrophic lateral sclerosis: the Piemonte and Valle d'Aosta Register. JAMA Neurol 2017;74:1097-104.

23 Uenal H, Rosenbohm A, Kufeldt J, et al. Incidence and geographical variation of amyotrophic lateral sclerosis (ALS) in Southern Germany-completeness of the ALS registry Swabia. PLoS One 2014;9:e93932.

24 Donaghy C, O'Toole O, Sheehan C, et al. An all-Ireland epidemiological study of MND 2004-2005. Eur J Neurol 2009:16:148-53.

25 Rojas-Garcia R, Scott KM, Roche JC, et al. No evidence for a large difference in ALS frequency in populations of African and European origin: a population based study in inner city London. Amyotroph Lateral Scler 2012;13:66-8.

26 Huisman $\mathrm{MH}$, de Jong SW, van Doormaal PT, et al. Population based epidemiology of amyotrophic lateral sclerosis using capture-recapture methodology. J Neurol Neurosurg Psychiatry 2011;82:1165-70.
27 Kab S, Moisan F, Preux PM, et al. Nationwide incidence of motor neuron disease using the French health insurance information system database. Amyotroph Lateral Scler Frontotemporal Degener 2017;18:426-33.

28 Arthur KC, Calvo A, Price TR, et al. Projected increase in amyotrophic lateral sclerosis from 2015 to 2040. Nat Commun 2016;7:12408.

$29 \mathrm{Kim} \mathrm{HJ}, \mathrm{Oh} \mathrm{KW}$, Kwon MJ, et al. Identification of mutations in Korean patients with amyotrophic lateral sclerosis using multigene panel testing. Neurobio/ Aging 2016;37:209.e9-209.e16

30 Kwon MJ, Baek W, Ki CS, et al. Screening of the SOD1, FUS, TARDBP, ANG, and OPTN mutations in Korean patients with familial and sporadic ALS. Neurobiol Aging 2012:33:1017.e17-1017.e23.

31 Kim YE, Oh KW, Kwon MJ, et al. De novo FUS mutations in 2 Korean patients with sporadic amyotrophic lateral sclerosis. Neurobiol Aging 2015;36:1604.e17-1604.e19.

32 Talbot K. Motor neuron disease: the bare essentials. Pract Neurol 2009;9:303-9.

33 Hogden A, Foley G, Henderson RD, et al. Amyotrophic lateral sclerosis: improving care with a multidisciplinary approach. J Multidiscip Healthc 2017;10:205-15.

34 Van den Berg JP, Kalmijn S, Lindeman E, et al. Multidisciplinary ALS care improves quality of life in patients with ALS. Neurology 2005;65:1264-7

35 Rooney J, Byrne S, Heverin $\mathrm{M}$, et al. A multidisciplinary clinic approach improves survival in ALS: a comparative study of ALS in Ireland and Northern Ireland. J Neurol Neurosurg Psychiatry 2015;86:496-501.

36 Shin J-Y, Lee K-W. Diagnosis and management of amyotrophic lateral sclerosis. J Korean Med Assoc 2015:58:131-8.

37 KCDC, 2018. Co-payment reduction. http://helpline.nih.go.kr/cdchelp/alrim.gst? method $=$ detailView\&ctype $=s$ (accessed 16 May 2018).

38 KCDC, 2018. Medical expenses support in rare intractable disease.http://helpline.nih. go.kr/cdchelp/alrim.gst?method=detailView\&ctype =m1 (accessed 16 May 2018)

39 Riviere $\mathrm{M}$, Meininger $\mathrm{V}$, Zeisser $\mathrm{P}$, et al. An analysis of extended survival in patients with amyotrophic lateral sclerosis treated with riluzole. Arch Neurol 1998:55:526-8

40 Miller RG, Mitchell JD, Lyon M, Moore DH, et al. Riluzole for amyotrophic lateral sclerosis (ALS)/motor neuron disease (MND). Cochrane Database Syst Rev 2002:CD001447

41 Bensimon G, Lacomblez L, Meininger V. A controlled trial of riluzole in amyotrophic lateral sclerosis. ALS/Riluzole Study Group. N Engl J Med 1994;330:585-91.

42 Knibb JA, Keren N, Kulka A, et al. A clinical tool for predicting survival in ALS. J Neurol Neurosurg Psychiatry 2016;87:1361-7.

43 FDA, 2018. Real world evidence. https://www.fda.gov/ScienceResearch/SpecialTopics/ RealWorldEvidence/default.htm (accessed 16 May 2018). 